\title{
Adapting to the events in Afghanistan: Call for maintaining essential public health services and supporting critical medical supplies distribution
}

\author{
Ahmed Al-Mandhari ${ }^{1}$ \\ ${ }^{1}$ Regional Director, World Health Organization Regional Office for the Eastern Mediterranean, Cairo, Egypt (Correspondence to: Ahmed Al-Mandhari: \\ almandharia@who.int).
}

Citation: Al-Mandhari A. Adapting to the events in Afghanistan to maintain essential public health services and support critical medical supplies distribution. East Mediterr Health J. 2021;27(9):855-856. https://doi.org/10.26719/2021.27.9.855

Copyright (C) World Health Organization (WHO) 2021. Open Access. Some rights reserved. This work is available under the CC BY-NC-SA 3.0 IGO license (https://creativecommons.org/licenses/by-nc-sa/3.o/igo).

The unfolding events in Afghanistan have recently left us with scenes of chaos and desperation at Kabul airport where men, women and children risked their lives, and some tragically died in efforts to flee the country. However, it is important to note that even before these latest events, Afghanistan was the world's third largest humanitarian operation due to war, displacement, and, of course, the COVID-19 pandemic (1). Over 18 million people - more than half the population - already need humanitarian assistance to survive, and these needs are increasing daily (1).

As the events quickly unfolded, the World Health Organization Regional Office for the Eastern Mediterranean has 2 priorities. First, to ensure the absolute safety of WHO staff in-country; a range of steps to increase the security and protection of staff and their dependents have been implemented, including relocating thousands of Afghan colleagues and their families out of harm's way to areas away from conflict. Second, to stay and deliver by continuing life-saving work for millions of Afghans who need assistance. This means prioritizing the delivery of life-saving supplies that health facilities badly need to stay operational, especially in Kabul, Kandahar and Kunduz. More than 500 metric tons of medicines and supplies remain in WHO warehouses in Dubai, but Kabul airport remains closed to commercial flights, and based on operational and security constraints, countries sending in empty planes to pick up evacuees do not feel they are able to help (2).

Over these years, WHO and partners have worked with authorities on multiple advances for the health and well-being of the people in Afghanistan, such as the Sehatmandi Project, which provides quality health, nutrition and family planning services across Afghanistan (3). Working together, a battered health system was strengthened by training health-care workers and delivering lifesaving and essential medicines, medical supplies and equipment. In addition, we monitored and responded to disease outbreaks, scaled up the trauma care programme, and ensured that services for women, mothers and children were available and accessible, even in the most remote and hard-to-reach areas.

As a result of the collective work of many partners and thousands of health-care workers, the number of women in Afghanistan dying in childbirth has reduced by $60 \%$ and child mortality has reduced by over $50 \%$. Almost $70 \%$ of all women now have a chance of surviving to the age of 65 , compared to only $54 \% 20$ years ago. It is more important than ever to keep building on these gains, so that every man, woman and child in Afghanistan has a chance to live a life filled with dignity, good health and hope (2).

However, other public health issues remain. Afghanistan remains one of only 2 countries in the world that has not eradicated wild poliovirus $(4,5)$. With only one child contracting wild poliovirus being reported in Afghanistan and Pakistan so far in 2019 and 2020, now is a critical time and an unprecedented opportunity for the programme in Afghanistan to eradicate polio and not lose the hard-won gains achieved so far.

In addition, it is essential to keep the COVID-19 pandemic under control where both Alpha and Delta variants have been documented in Afghanistan (6-8). Overcrowding among displaced people has limited infection prevention measures and increased the risk of transmission of different type of infections. Concerns remain that a new spike among displaced people could lead to further transmission across cities due to a very low vaccination rate of just 5\%; Afghanistan has reported over 153000 COVID-19 cases and more than 7000 deaths as of 3 September 2021 (9).

The resulting instability has put some key measures to strengthen the COVID-19 response on hold, including the establishment of new laboratories for testing, the installation of oxygen plants in hospitals, and the expansion of isolation centres and intensive care beds for COVID-19 in different provinces of Afghanistan. It has also made implementation of infection prevention measures extremely difficult across the country and impacted the COVID-19 vaccination programme. As well as COVID-19-like symptoms among displaced persons, there have been reports of an increase in cases of diarrhoea, high blood pressure, and reproductive health complications and malnutrition (2).

As needs increase, WHO continues working in coordination with health partners. Six medical teams have been deployed during August 2021 in Kabul to 
provide lifesaving emergency primary health care services to more than 100000 displaced people (2). The first shipment of medical supplies was secured on 30 August and subsequent shipments are under process. Fourteen medical teams were deployed to provide health services in the eastern region of the country (2). Overall, more than 3000 medical consultations have been provided, including outpatient, antenatal and post-natal care, immunization, and screening for malnutrition (2). 130 WHO-supported trauma care health facilities remained open, providing case management services (2).

Critical polio surveillance activities continued largely undisrupted and polio vaccinations are continuing to be administered to children through permanent transit teams in most regions and at cross-border sites, including Friendship Gate (between Afghanistan and Pakistan) (10). In addition, WHO has delivered trauma kits, basic medical supplies and cholera kits to health facilities in Bamyan, Daikundi, Ghazni, Helmand, Kabul and Kunduz provinces. These supplies are enough to cover the urgent health care needs of 152700 people (2). Medicines and supplies were also dispatched to 22 malnutrition centres treating children with severe acute malnutrition (2).

Nevertheless, there isstill urgentneed for reproductive- child health services, mental health services, mosquito nets and hygiene kits for newly displaced people. Nutrition supplements are needed to address rising malnutrition among children, especially those affected by conflict. COVID-19 and other routine immunization, including polio vaccination, must continue without interruption to control infectious diseases and prevent secondary health emergencies. Moreover, injured people - including women and children - need trauma care, as well as longer term rehabilitation to prevent life-long injuries. Mental health services are also needed now more than ever before.

As the current events continue to unfold, WHO is fully committed to staying and delivering in Afghanistan. Today, WHO has a network of 684 staff and health workers inside the country working in all 34 provinces. We now need the support of our donors and partners to count on us, work with us, and help us save lives, promote health and serve the vulnerable. The health and well-being of the Afghani population continue to remain one of our top priorities, based on WHO's regional vision of 'Health for All by All - a call for solidarity and action' (11), and it remains our goal to fulfil this vision for Afghanistan.

\section{References}

1. World Health Organization Regional Office for the Eastern Mediterranean (WHO/EMRO). WHO Regional Director's statement on Afghanistan. Cairo: WHO/EMRO; 2021 (http://www.emro.who.int/media/news/who-regional-directors-statement-on-afghanistan-24-august-2021.html).

2. World Health Organization Regional Office for the Eastern Mediterranean (WHO/EMRO). Statement by the WHO Representative in Afghanistan. Cairo: WHO/EMRO; 2021 (http://www.emro.who.int/afg/afghanistan-news/statement-by-the-who-representative-on-afghanistan.html).

3. The World Bank. Delivering strong and sustained health gains in Afghanistan: The Sehatmandi Project. Washington, DC: The World Bank; 2020 (https://www.worldbank.org/en/results/2020/10/23/delivering-strong-and-sustained-health-gains-in-afghanistan-the-sehatmandi-project).

4. World Health Organization. Pakistan and Afghanistan: the final wild poliovirus bastion. Geneva: World Health Organization; 2019 (https://www.who.int/news-room/feature-stories/detail/pakistan-and-afghanistan-the-final-wild-poliovirus-bastion).

5. Alwan A; Maher C. Closer to a polio-free Eastern Mediterranean Region. East Mediterr Health J. 2016;22(9):645-646 https://doi. org/10.26719/2016.22.9.645

6. Al-Mandhari A; Marmot M; Ghaffar A; Hajjeh R; Allen J; Khan W; et al. COVID-19 pandemic: a unique opportunity to 'build back fairer' and reduce health inequities in the Eastern Mediterranean Region. East Mediterr Health J. 2021;27(3):217-219 https://doi. org/10.26719/2021.27.3.217

7. $\quad$ Basij-Rasikh S; Khalil M; Safi N. Early responses to COVID-19 in Afghanistan. East Mediterr Health J. 2020;26(12):1442-1445. https://doi.org/10.26719/emhj.20.137

8. Mowafi H; Sakr H; Ravaghi H; Elmahal O; Slama S; Samhouri D; et al. Leveraging the COVID-19 response to improve emergency care systems in the Eastern Mediterranean Region. East Mediterr Health J. 2020;26(6):626-629 https://doi. org/10.26719/2020.26.6.626

9. World Health Organization. Global dashboard - Afghanistan. Geneva: World Health Organization; 2021 (https://covid19.who.int/ region/emro/country/af).

10. World Health Organization. Statement following the Twenty-Eighth IHR Emergency Committee for Polio. Geneva: World Health Organization; 2021 (https://www.who.int/news/item/21-05-2021-statement-following-the-twenty-eighth-ihr-emergency-committee-for-polio).

11. World Health Organization Regional Office for the Eastern Mediterranean (WHO/EMRO). Vision 2023 Eastern Mediterranean Region: health for all by all - a call for solidarity and action. Cairo: WHO/EMRO; 2018 (https://apps.who.int/iris/handle/10665/326911). 